members' scientific academies, the communiqué declined to acknowledge explicitly either the serious threat posed by climate change, or the established facts regarding the central role of fossilfuel consumption in that threat. It contains some very soft language about the need to "slow and, as the science justifies, stop and then reverse the growth of greenhouse gases".

It is little wonder that environmental groups, and some scientific institutions such as Britain's Royal Society, have roundly denounced the climate communiqué. But even in this verbose document, optimists can unearth some evidence of progress. All of its signatories, including US President George Bush, acknowledge that fossil fuels "contribute in large part to increases in greenhouse gases associated with the warming of our Earth's surface". Some people are interpreting this deliberately vague sentence as evidence that Bush is slowly accepting the science of climate change.

The communiqué also reaffirmed the role of the United Nations Framework Convention on Climate Change (UNFCCC) in responding to climate change. It now falls to the next Conference of the Parties to the UNFCCC in Montreal this autumn to use any political tail wind from the summit to come up with a plan that

looks beyond 2012 and will follow on from the Kyoto Protocol. If that plan contains more flexible, market-led approaches towards promoting cleaner energy supplies and industry than did the Kyoto Protocol, and incorporates meaningful participation by developing countries, there is a chance that the United States will eventually rejoin the process.

By the 2008 G8 meeting in Japan, when the leaders are committed to revisiting the climate-change issue, it is even possible that the United States will be in the throes of a presidential campaign between two main candidates who are each committed to taking the issue seriously.

In the end, the communiqué from the summit meeting may have contained rather fewer

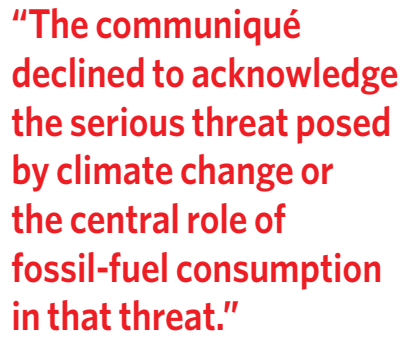

concrete steps than Blair hoped for when he set out the agenda. But at least it succeeded in elevating the public profile of two of the most important questions that face humanity.

\title{
Diversionary tactics
}

\section{A map in a Nature supplement is being used to divert debate about science funding in China.}

T here are good scientists from the island of Taiwan. There are good scientists from mainland China. When Nature publishes a paper from Chinese scientists, whether they come from one or the other is not an issue. And whether Taiwan is an independent country - certainly an important and sensitive matter - is not an issue on which Nature takes a stand.

It is unfortunate, therefore, that the significance of a map of China in a Nature publication has been blown out of proportion and, reportedly, used by some bureaucrats to block several of the supplement's commentaries from wide dissemination.

The map appeared last November in China Voices II, a Chinese language supplement devoted to science and science policy in China (and a successor to a similar supplement that was well received a year previously). The map did not show Taiwan. Many Chinese who saw the map admit that they

"Issues of science
funding such as
these are universal,
controversial, and benefit
from open, critically
minded discussion."
did not even notice the omission, but some immediately claimed that it was a deliberate attempt to portray Taiwan as an independent state.

When Nature specifies Taiwan's status, we follow the convention set by the United Nations and describe it either as a 'region' or an island. The map was originally inserted for decorative purposes, and so in recognition of the acute sensitivity in China of the issue of Taiwanese independence, and in view of our neutral position on the question, Nature promptly rounded up all the copies of the supplement and destroyed them (a couple of hundred had already been distributed). We then printed several thousand copies of a new version - with no map.

And yet the distribution of the revised supplement continues to be obstructed. At a February session of China's National Congress, officials from the Ministry of Science and Technology were reportedly running about with copies of the original version claiming that Nature was in a conspiracy to rip Taiwan from the mainland.

Why have the ministry's bureaucrats reacted in this way? In reality, sources say, they were upset by the content of some of the essays, which were critical of China's science policy. They have sought to use the map controversy to divert attention from the real issues.

The spirit of the supplement was to support the healthy development of science in China, and all articles were written by scientists working in China or intimate with it. Some articles in the supplement are critical. One takes China to task for ploughing too much of its science budget into large, long-term, applied research projects at the expense of smaller-scale, basic science in which, the author argues, individual creativity can flower. Another, more pointed still, cites the lack of peer review in most grant allocation and calls on the Ministry of Science and Technology to surrender control of its sciencebudget to organizations better able to distribute the funds where they are needed most. (In fact, the office of the Minister of Science and Technology turned down an offer to write a commentary for the supplement.)

Issues of science funding such as these are universal, controversial, and benefit from open, critically minded discussion in many countries. The supplement (copies of which can be obtained from chinavoices@naturejpn.com) was intended to foster such debate within China and in the worldwide Chinese community. But such discussion should not be diverted by a false characterization of Nature's intentions. 